\title{
The perceptions and preferences of medical students regarding large group teaching in Sri Venkateswara medical college, Tirupati, Andhra Pradesh, India
}

\author{
M Ramadevi $^{1^{*}}$, C. Jaya Bhaskar ${ }^{2}$ \\ ${ }^{\mathbf{1}}$ Assistant Professor, ${ }^{2}$ Professor, Dept. of General Medicine, S.V. Medical College, Tirupati, Andhra Pradesh, India
}

*Corresponding Author: M Ramadevi

Email: ramadevimdgm@gmail.com

\begin{abstract}
Lecture is an important mode of sharing and providing knowledge to a large group of students in a specified time and place. Medical curriculum is changing from time to time and evaluation of curriculum is a routine process by the experts. However the opinion of students is important because they are at the recipient end. Changes in the curriculum can be adopted by considering their opinion.

Objectives: To study the perceptions and preferences of the medical students about large group teaching.

Methodology: A cross sectional descriptive study is taken among 459 medical students of Sri Venkateswara Medical College, Tirupati, A. P. after informed consent. A validated questionnaire is administered to the students. Answered questionnaires are analyzed.

Results: $85 \%$ of the students participated; $91 \%, 81 \%$ and $80 \%$ of pre, para and clinical year students respectively. Most of the students are not satisfied with the present day teaching by using PPT. They prefer black board teaching and using of PPT whenever necessary with better audio visual aids and improved class room environment.

Conclusions: This survey identifies many defects in the essential component of medical curriculum i.e., teaching. Improving the skills of teaching in medical teachers and improving the facilities in the lecture halls, so that the students can learn in a better manner to become effective primary care physicians in the society.
\end{abstract}

Keywords: Large group teaching, Medical curriculum, Audio-visual aids, MCQ's.

\section{Introduction}

Learning is an active process in which student and teacher have to work mutually. The oldest conventional method of transferring information to a large group of audience is teacher centered lectures and makes learning passive. Concepts such as flexibility in learning, problem solving, critical thinking and independent learning are least recognized in classroom lectures. Medical curriculum is changing from time to time. It becomes essential to utilize an approach to teaching and learning that is best suited to the needs of students. However students' opinions and preferences in large group teaching is equally important because they are at the recipient end. Taking into account these perceptions and preferences for improvement of medical curriculum, the present study is taken.

\section{Objectives}

1. To understand the perceptions of medical students about the large group teaching.

2. To identify the barriers in learning process as perceived by the students.

3. To know the preferences of medical students in large group teaching.

\section{Materials and Methods}

A cross sectional descriptive study of 459 pre, para and clinical year medical students of Sri Venkateswara Medical College, Tirupati, Andhra Pradesh, India. Informed written consent is taken from the students after explaining the purpose of the study. A validated questionnaire is administered to the participant students. Answered questionnaires are analyzed.

\section{Results and Discussion}

Of the 542 students in the pre clinical, para clinical and clinical years, $85 \%$ of the students (459) a participated in the study. $92 \%$ of pre clinical year students, $81 \%$ of Para clinical year students and $80 \%$ of clinical year students are included in the present study.

\section{Perceptions of Students \\ Large group teaching}

$32 \%$ of the pre clinical students opined that large group teaching should be avoided. $49 \%, 83 \%$, and $50 \%$ of the pre, para and clinical year students respectively perceived that classes are very boring without any fun. Poor PPT preparation and presentation are percieved by $27 \%, 29.7 \%$ and $41 \%$ of preclinical, paraclinical and clinical year students respectively. Lack of interaction between students and teacher is perceived by $33.6 \%$ preclinical and $44.3 \%$ paraclinical students. $48.9 \%$ of preclinical students perceived poor audiovisual aids in the classroom.

Pre, para and clinical year students reported lack of concentration in the class because of continuous prolonged classes. Students perceived lack of discipline among themselves which create loss of concentration in the class.

\section{Preferences of students}

$77 \%$ of Para and $43 \%$ of clinical year students preferred black board teaching. They prefer only PPT for summarizing the topic. Preclinical students preferred 3D videos with good audio visual aids(51\%).

Most of the Pre, Para and clinical year students prefer time gap between the classes. $13 \%$ of the Clinical year students prefer prior intimation of the topic. 
Asking questions in the class, MCQ's, seminars and periodic assessments are preferred by the para clinical and clinical students which improves the relation between students and teacher. Most of the students want Concept oriented teaching, repetition and summarization of the topic at the end. This type of teaching will retain the subject and improves the reproducibility. $16 \%, 12 \%, 21 \%$ of pre, para, clinical year students prefer a shorter duration of class to 45 minutes. Students want an improvement of the facilities in lecture halls. Some students want a special class for clearing the doubts at weekends.

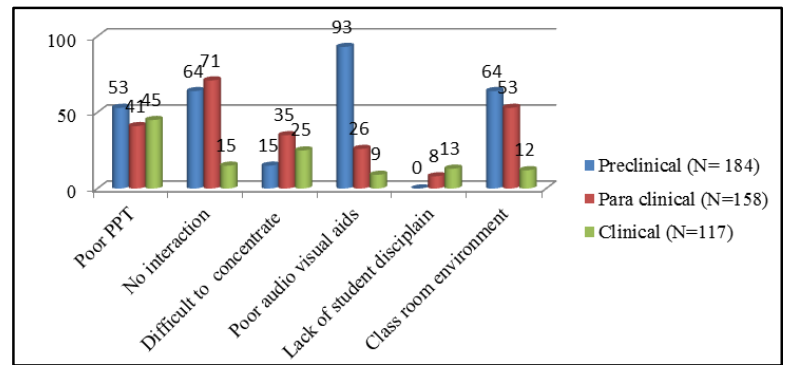

Fig. 1

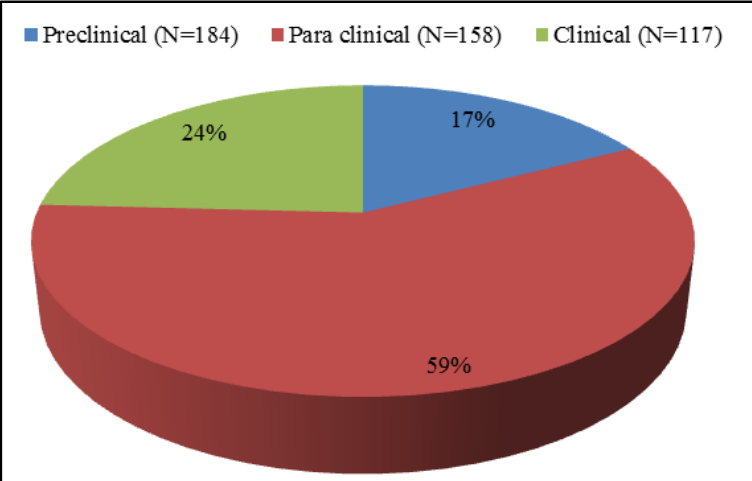

Fig. 2: Prefer black board

Many studies like Priyadarshini et al, Chaudhary et al, Roopa Kulakarni et al support the use of black board teaching, use of multimedia, better audio visual aids and shorter duration of lectures. These were effective in creating an interest among students, retaining the subject and improving reproducibility.

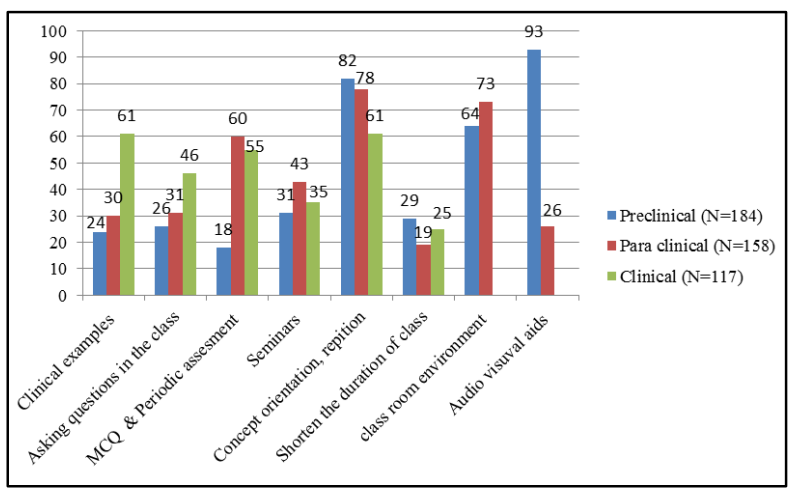

Fig. 3

\section{Conclusion}

This survey identifies many defects in the essential component of medical curriculum i.e. Organization of lecture and way of teaching. It addresses that a lot of improvement is required by the medical teachers to enhance the skills of teaching in medical education and also college administration to improve the facilities in the lecture halls, so that the students can learn in a better manner to become effective primary care physicians in the society.

\section{Acknowledgment \\ CMC, Vellore.}

\section{Source of Funding}

None.

\section{Conflict of Interest}

None.

\section{References}

1. Kulakarni R, Aswini CA, Reddy B. Student perception on lecture in medical education. Anatomica Karnataka. 2011;5(2):1-9.

2. Ujwala U, Padmasree D, Dhruvs C. Lecture delivering -an emperical investigation of undergraduate medical students perceptions and preferences. Natl J R Comm Med. 2014;3(2):152-7.

How to cite: Ramadevi M, Bhaskar CJ. The perceptions and preferences of medical students regarding large group teaching in Sri Venkateswara medical college, Tirupati, Andhra Pradesh, India. J Educ Technol Health Sci. 2020;7(1):23-4. 